\title{
RECICLAGEM DE ÓLEOS RESIDUAIS DE ESTABELECIMENTOS GASTRONÔMICOS NA CIDADE DE JAGUARARI (BA) POR MEIO DA EDUCAÇÃO AMBIENTAL
}

\author{
Maria José Souza Pinho ${ }^{1}$ \\ Juraleson Leite Santos ${ }^{2}$
}

Resumo: No presente relato de experiência, apresentam-se considerações acerca de um projeto de extensão com duração de 01(um) ano, desenvolvido na cidade de Jaguarari na Bahia, com representantes do setor gastronômico do mercado, mulheres do grupo de oração das igrejas católica e evangélica e discentes de uma escola municipal. O objetivo foi mobilizar a comunidade para a questão da responsabilidade socioambiental, mediante a coleta de óleo residual de frituras e sua transformação em sabão artesanal. As etapas do projeto foram: levantamento dos conhecimentos prévios, ações de sensibilização e informação e, por fim, as oficinas de reciclagem. Assim, percebemos que educar ambientalmente vai além da sensibilização da população; é preciso, sobretudo, mobilização e ação.

Palavras-chave: Educação Ambiental; Reciclagem de óleo; Sustentabilidade. 


\section{Introdução}

O elevado nível de consumo dos produtos industrializados gera um enorme volume de lixo que, inevitavelmente, será descartado. Essa prática é consequência do aumento populacional, do surgimento de novas tecnologias e do consumismo desenfreado, de modo que uma quantidade cada vez maior de resíduos oriundos dessa produção vai se constituir como um dos fatores responsáveis pelo aumento da emissão de poluentes no meio ambiente (COELHO, 2010).

Pensando nisso, procuramos uma forma de colaborar para diminuir a quantidade de resíduos descartados de forma incorreta na natureza, visto que eles podem ser reutilizados ou reciclados e, com isso, podem minimizar os impactos que provocam.

Dentre os resíduos produzidos em nossa sociedade, escolhemos o óleo residual de fritura, porque este ganha destaque à medida que the é agregado valor econômico depois da reciclagem.

As possibilidades de reciclagem dos óleos são inúmeras. Segundo Reis e Fleck (2009), os óleos podem ser transformados em glicerina pela reação de saponificação e usados em diversos materiais, a saber, na composição de certas tintas (no caso dos óleos vegetais insaturados secativos), após padronização; na produção de massa de vidraceiro; na produção da farinha básica para ração animal; na queima em caldeiras e, ainda, na produção de biodiesel.

Indicadores apontam um aumento significativo no uso de alimentos fritos pela população, talvez porque a fritura é uma operação de preparo rápido, conferindo aos alimentos fritados "características únicas de saciedade, aroma, sabor e palatabilidade" (REIS; FLECK, 2009, p.2).

Convém lembrar que o consumo desmedido de ácidos graxos (compostos por triglicerídeos), presentes em alimentos fritos, favorece o aumento de doenças no ser humano como, por exemplo, aumento do colesterol Low Density Lipoprotein (LDL), entupimento de artérias e doenças crônicas (as cardiovasculares, o diabetes e a hipertensão arterial).

Quando óleos e graxas atingem corpos d'água (rios, lagos e mares), são degradados pelos micro-organismos presentes, em especial as bactérias, que, neste processo, consomem o oxigênio dissolvido. A escassez do oxigênio causa a morte da fauna aquática. Há ainda outro impacto associado à viscosidade e tensão superficial do óleo que conduz à formação de filme flotante na superfície, atuando como barreira, prejudicando a aeração pelo vento (SABESP, 2008). Por ser menos denso que a água, o óleo de oleaginosas forma uma película sobre ela. Ainda provoca a retenção de sólidos, entupimentos e problemas de drenagem, quando despejado em pias ou vasos sanitários, que são redes coletoras de esgoto (SALLES, 2010). A prática de lançar óleo de cozinha diretamente na rede de esgoto proporciona o entupimento da tubulação e refluxo de esgoto, entre outros problemas. 
A fim de melhor compreender a forma de utilização e eventual reutilização do óleo proveniente de frituras e eventuais impactos no meio ambiente, causados pelo descarte desses produtos (óleo e graxa), feito de forma inadequada, tomamos, para fins de pesquisa, os procedimentos adotados em lanchonetes e restaurantes instalados na feira livre, em espaço coberto, da Praça Lauro de Freitas. Essa praça localiza-se na sede do município de Jaguarari na Bahia e é cenário de implantação e desenvolvimento do projeto "Recicla-Óleo: reaproveitamento e sustentabilidade".

As lanchonetes são um destaque neste trabalho, pois utilizam grande quantidade de óleo vegetal diariamente no preparo de alimentos. Os restaurantes fornecem refeições variadas, utilizando-se de muitas frituras. Do total de óleo utilizado diariamente no preparo de alimentos, uma grande parcela das sobras é descartada diretamente nos ralos, nas pias e no lixo, junto com outros resíduos.

Planejamos a realização de uma oficina de reciclagem de sabão com os alunos da Escola Municipal e essa decisão foi importante por eles serem clientes, em potencial, destes estabelecimentos e, dessa forma, poderiam conscientizar-se sobre a temática.

Optamos, ainda, por realizar a oficina com mulheres do grupo de oração das igrejas católica e evangélica da cidade, porque percebemos a possibilidade de gerar renda com a produção de sabão.

Essa práxis de Educação Ambiental, usando os princípios da reciclagem, coaduna-se com a política dos 5Rs (Reduzir, Reutilizar, Reaproveitar, Reciclar e Repensar) e é uma forma de contribuir para a preservação e a sustentabilidade dos recursos naturais de nossa cidade.

Inicialmente, o que nos despertou o interesse para desenvolver esse projeto foi a visualização de resíduos de óleo em esgoto, lançado nos rios (caráter temporário) que cortam a cidade de Jaguarari, contaminando as bacias do Rio São Francisco e do Rio Itapicuru.

A logística reversa permite que óleo e graxas pós-uso retornem ao mercado sob a forma de sabão, minimizando a poluição dos recursos hídricos. Isso justifica a abordagem do trabalho com resíduos de óleos além da carência/fragilidade das políticas públicas, em âmbito local, no que se refere aos programas, projetos e às ações que estimulem as práticas de reciclagem, principalmente com o intuito de provocar mudanças estruturais de consciência.

Fomentar o hábito da coleta seletiva de óleo residual de frituras em estabelecimentos comerciais, reduzir o descarte incorreto de óleo e graxas em pias e ralos; desonerar os órgãos públicos municipais dos gastos com manutenção do sistema de esgotamento da praça de alimentação e minimizar a contaminação dos efluentes no meio ambiente são ações que oferecem ganhos econômicos, sanitários e ambientais para a população em geral, de modo que essa experiência incrementada prevê uma interferência positiva na qualidade de vida dessa população. 


\section{Matéria prima: óleo}

O óleo é originário basicamente dos vegetais, especificamente das sementes, a exemplo do óleo de algodão (Gossypium hisutum L.), de amendoim (Arachis hypogaea L.), de milho (Zea mays L.) e de soja (Glicyne max (L.) Merrill). A gordura advém principalmente dos animais. Seus fins são diversos, mas é, principalmente, destinado ao preparo de alimentos e produtos industrializados (SALLES, 2010). O óleo vegetal é a junção de moléculas de glicerol e ácidos graxos insaturados, definidos como triglicerídeos e classificados como lipídeos (LOPES; ROSSO, 2005).

A localização geográfica e climática do Brasil favorece a expansão da agricultura e o cultivo de espécies vegetais oleaginosas. Os óleos dessas plantas são extraídos principalmente para o consumo humano.

Tendo inúmeras espécies cultivadas, "o Brasil produz 9 bilhões de litros de óleos vegetais por ano. Desse volume produzido, um terço constitui óleos comestíveis. O consumo per capita fica em torno de 20 litros/ano" (FILHO, et al., 2010, p. 68).

Ao adquirirem característica imprópria para o consumo, as sobras de óleos e graxas usadas em frituras de alimentos são descartadas inadequadamente nas pias, ralos e lixo. Essa prática provoca, entre outros problemas, os seguintes: i) obstrui a rede de esgoto; ii) encarece o custo da manutenção das redes coletoras de esgoto; iii) onera os órgãos públicos com gastos para recolher o esgoto e tratá-lo; iv) impermeabiliza o solo; v) polui os ecossistemas e vi) dificulta a troca gasosa entre a água e atmosfera por ser menos denso, contribuindo para o aumento do efeito-estufa e para a contaminação dos recursos hídricos (NEZI; UHDRE; ROMERO, 2011, RABELO; FERREIRA, 2008).

Essa, portanto, é a nossa principal matéria-prima para a confecção de sabão caseiro, evitando, através do ciclo reverso, a degradação ambiental.

\section{Estratégia: Educação Ambiental}

A Educação Ambiental (EA) propõe a construção do conhecimento no processo de conservação da natureza, à medida que a humanidade participa de ações mitigadoras de conservação e preservação dos recursos naturais (MEDINA; SANTOS, 2001).

A educação contemporânea proposta aqui apoia-se na metodologia construtivista, pois permite compartilhar atitudes que minimizem os efeitos negativos dos impactos causados pelos resíduos do óleo de cozinha, com o simples hábito de repensar, reduzir, reutilizar, reaproveitar e reciclar.

Nesse contexto, a EA é vista como uma projeção de grande relevância, em função da capacidade de intervir em atitudes demasiado contrárias à natureza.

Apoiada nos Parâmetros Curriculares Nacionais (BRASIL, 1998) Revbea, São Paulo, V. 12, № 2: 102-113, 2017.

revista brasileira

educação ambiental 
relativos ao Meio Ambiente, a EA proposta neste trabalho traz práticas educativas que priorizam a vivência do discente de uma forma contextualizada, com ações interdisciplinares que permitem desenvolver noções de preservação e sustentabilidade, entendendo que a educação é:

um meio indispensável para se conseguir criar e aplicar formas cada vez mais sustentáveis, de interação sociedade-natureza, e soluções para os problemas ambientais. A educação sozinha não é suficiente para mudar os rumos do planeta, mas certamente é condição necessária para tanto (BRASIL, 1998, p.180).

Objetivamente, isso significa dizer que esse ato educativo não se pauta pela transmissão de informações, de conhecimentos, como se isso, per si, fosse suficiente, mas pela práxis educativa com a indissociável relação entre teoria e prática que ganha a devida centralidade na transformação humana. Essa EA, voltada para a formação humana, associa o conhecimento ambiental, científico e político-social promovendo a participação ativa das pessoas, a autonomia de grupos sociais e o direito à informação, à tomada de decisão, à aquisição de habilidade e à mudança de atitude (LOUREIRO, 2012).

Destarte, o "indivíduo e a comunidade passam a ter conhecimento do meio ambiente, de forma a torná-los aptos a agir, individual ou coletivamente, $e$ a resolver problemas ambientais" (MANO; PACHECO; BONELLI, 2005, p.93), pois são capazes de problematizar a realidade local.

Neste enfoque de EA, um conceito é agregado ao processo: a sustentabilidade. A educação é sempre uma prioridade para criar estratégias de promoção de sustentabilidade, pois é entendida como um dos instrumentos fundamentais e indispensáveis nos processos de gerenciamento de recursos naturais. A EA, que visa a sustentabilidade da vida, deve substanciar-se pela promoção do sentimento de pertencimento solidário (SACHS, 2009), permeado pela ética do cuidado. Reconhecendo mudanças de comportamento, poderá gerar um futuro mais sustentável em termos de integridade socioambiental.

Nesse sentido, a EA permite parafrasear o pensamento de Freire ao dizer que a conscientização só tem sentido quando é movida pelo diálogo, pela reflexão e ação no mundo.

\section{Percurso metodológico}

\section{Área de estudo}

O cenário de aplicação do projeto "Recicla-óleo: reciclagem e sustentabilidade" foram restaurantes e lanchonetes da praça de alimentação (Figura 1), localizada na sede do município de Jaguarari na Bahia. Tal praça é composta de 41 boxes, sendo 17 destinados ao segmento gastronômico. Além disso, esse espaço agrega, em suas laterais, aproximadamente 300 
comerciantes de frutas e verduras. As lanchonetes fornecem uma grande quantidade de alimentos fritos, pois situa-se no centro comercial da cidade (Praça Lauro de Freitas) e são frequentadas por um número muito grande de pessoas diariamente.

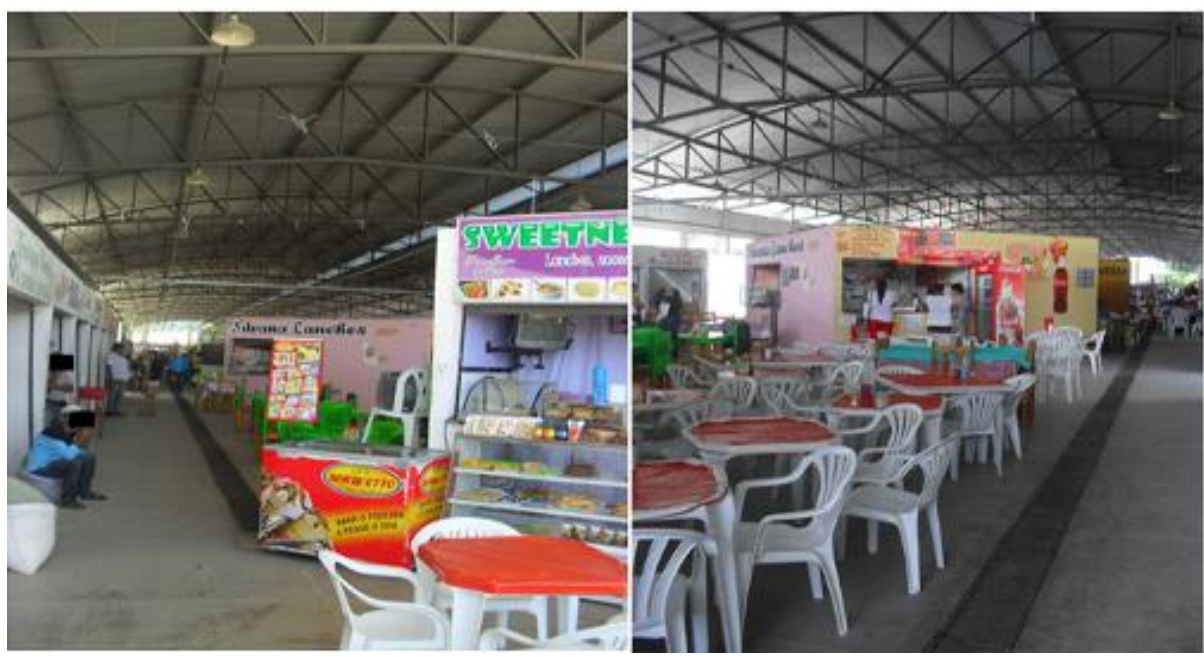

Figura 1: Praça de alimentação do munícipio de Jaguarari, BA, onde foi realizada a intervenção. Fonte: acervo pessoal dos autores (2014)

A outra área onde aplicamos o projeto foi a Escola Municipal João Ferreira de Matos (JFM) (Figura 2), situada na Praça Demóstenes Barbosa, localizada a 200 metros da praça de alimentação. Os alunos, portanto, frequentam e lancham nesses estabelecimentos já que estes são próximos à escola e também pela presença de familiares que são proprietários de boxes de lanchonetes.

A unidade escolar funcionou em 2014 nos três turnos com 10 salas de aulas, atendendo 450 estudantes.

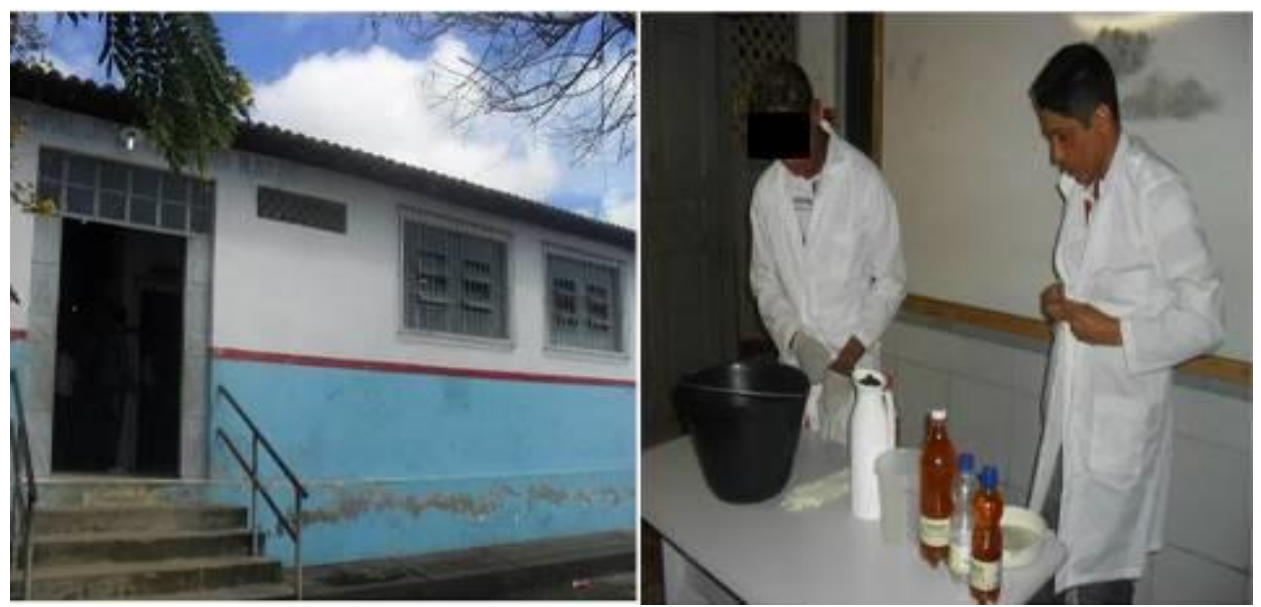

Figura 2: Vista frontal da escola J.F M e oficina de sabão realizada com alunos desta unidade. Fonte: acervo pessoal dos autores (2014) 


\section{Procedimentos adotados}

De posse da autorização do Diretor de Serviço de Atendimento ao Cidadão, responsável pela praça de alimentação da feira coberta, para a aplicação do projeto Recicla-Óleo, realizamos um trabalho de sensibilização com os proprietários dos estabelecimentos gastronômicos sobre a importância do projeto, de modo a estreitar a contribuição deles.

Obtivemos os dados através da aplicação de um questionário semiestruturado, com a finalidade de quantificar o óleo usado, por mês, no preparo de alimentos e sua forma de descarte, entre outras questões.

Distribuímos aos proprietários dos restaurantes e lanchonetes da praça de alimentação garrafas plásticas (PET de 2l) padronizadas com o símbolo do projeto Recicla-Óleo, para a coleta e o armazenamento do óleo residual (Figura 3). Posteriormente, tais garrafas foram recolhidas pelos alunos da escola, pelas mulheres do grupo de oração e pelo monitor do projeto, a cada oito dias em lanchonetes e a cada dez dias em restaurantes, para a confecção do sabão.
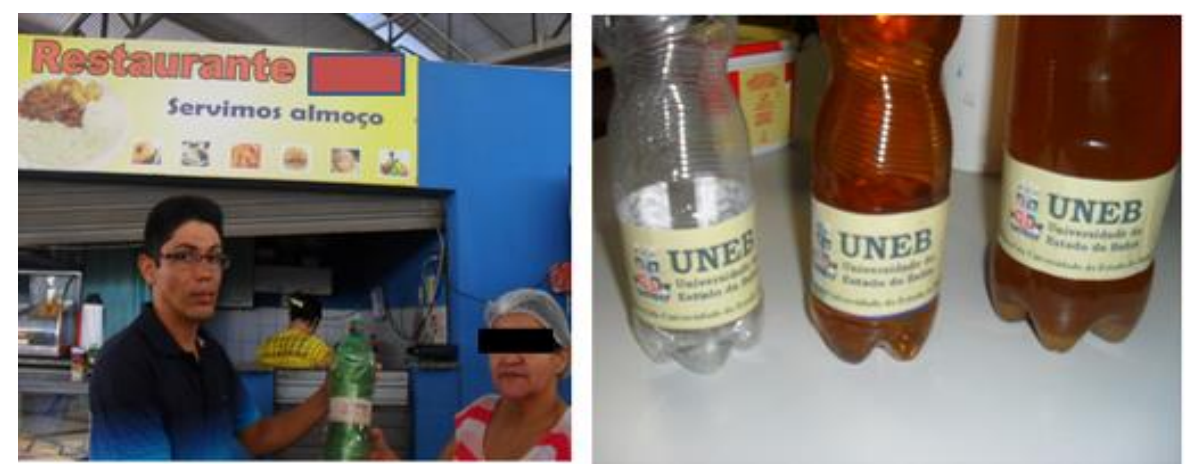

Figura 3: Pesquisador realizando a distribuição de recipiente para armazenagem de óleo residual de fritura de lanchonetes e restaurantes. Fonte: acervo pessoal dos autores (2014)

Ao mesmo tempo, realizamos oficinas de sensibilização com os alunos da Escola Municipal João Ferreira de Matos, fazendo distribuição de fôlderes (Figura 4) nos quais expúnhamos os principais problemas do descarte de óleo e graxas no meio ambiente e utilizando dinâmicas que promovessem a reflexão e provocassem nos alunos a vontade de participar, ativa e coletivamente, na gestão dos resíduos de frituras.

Ao coletar o óleo nos estabelecimentos da praça de alimentação, realizamos oficinas de produção de sabão caseiro com a participação de 10 (dez) mulheres do grupo de oração e com os alunos do turno noturno, por apresentarem maior faixa etária, já que íamos utilizar a soda cáustica na fabricação do sabão. 

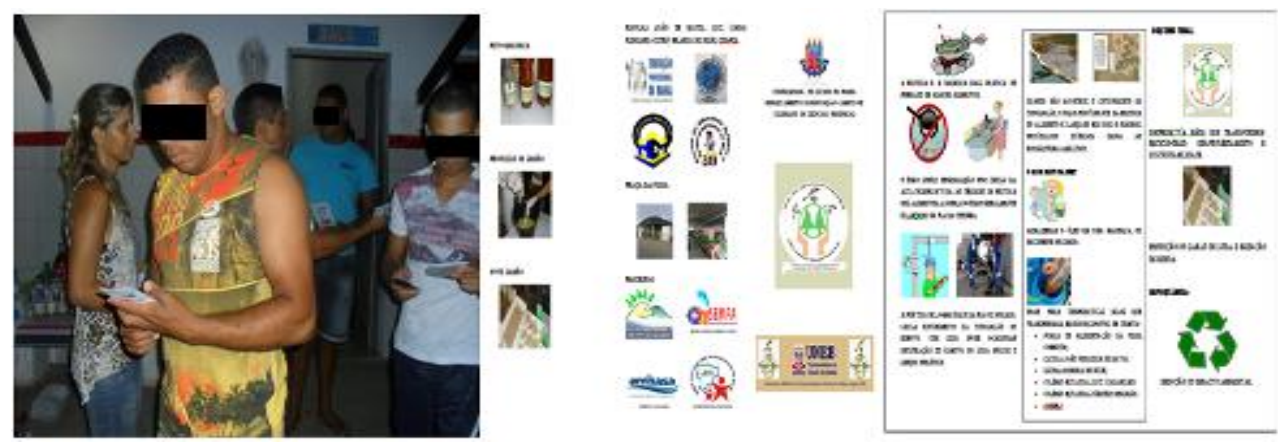

Figura 4: Distribuição de fôlder informativo sobre resíduos de frituras.

Fonte: acervo pessoal dos autores (2014)

Nas oficinas, utilizamos também material de proteção como luva, máscara e avental. Ali, para confeccionar sabão artesanal com as mulheres do grupo de oração, testamos receitas observando o custo-benefício da produção e buscando a melhor qualidade do produto. Para tanto, foram observadas características como a capacidade de espumar, o odor, a consistência, por meio de um questionário de satisfação do produto. Do total de 10 pesquisadas, 07 informaram que a adição de produtos como essência foi muito importante para melhorar a qualidade do sabão manufaturado. A única característica não avaliada foi o potencial hidrogeniônico $(\mathrm{pH})$.

\section{Resultados e discussão}

Os resultados obtidos a partir da pesquisa revelam que $41,4 \%$ dos estabelecimentos comerciais da Praça Lauro de Feitas são ligados ao setor gastronômico. Dentre estes, os que mais ganham destaque são as lanchonetes, em função da venda diária de lanches rápidos, baratos e, na maioria das vezes, de alimentos fritos, como coxinhas, pastéis, quibes, entre outros. Os restaurantes fornecem refeições variadas e utilizam também o óleo para frituras de frango, carne do sol ou peixe. No total, para as lanchonetes e para os restaurantes, são comprados 364 litros de óleo por mês, aproximadamente, os quais são utilizados no preparo de refeições, o que é referendado pelo consumo no Brasil. Segundo pesquisas, o consumo fica em torno de nove bilhões de litros de óleo vegetal por ano (OIL WORLD, 2014).

A rotina dos proprietários de estabelecimentos da praça de alimentação revela, quanto ao descarte, que $46,6 \%$ dos comerciantes descartavam os óleos e graxas na pia, no ralo e no lixo doméstico. A forma de descarte de maneira inadequada nos faz constatar que eles ainda não conseguem associar esse ato a uma preocupação com o destino final. A única coisa que importa é se livrar do lixo gerado por eles mesmos.

Ainda sobre a preocupação do descarte, $73,3 \%$ dos proprietários desconhecem os impactos causados pela disposição inadequada do óleo de fritura no meio ambiente e não a relacionam com a qualidade de água dos rios da cidade. Antes de descartarem o produto final de frituras, 53, 3\% reutilizamno em outras frituras, por uma ou duas vezes (Gráfico 1).

revista brasileira educação ambiental 


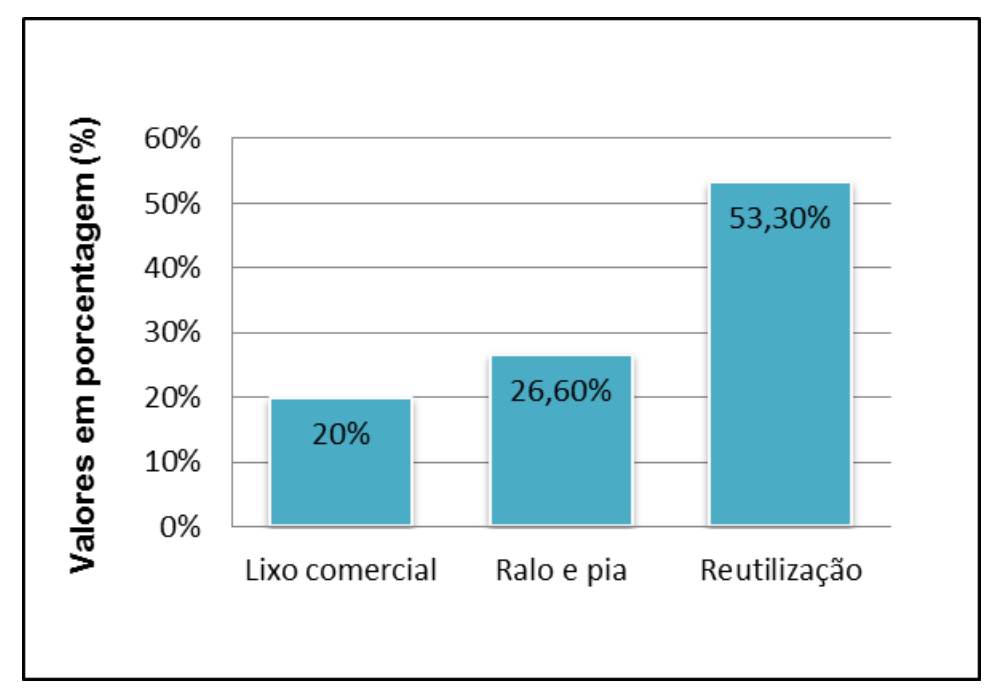

Gráfico 1: Destino do óleo de fritura dos restaurantes e lanchonetes do mercado coberto no munício de Jaguarari (BA). Fonte: elaboração dos autores (2014).

Reis et al. (2009) afirmam que o óleo é exposto à oxidação, ao ser aquecido na presença de ar e, ao reagir com diversos agentes (ar, água, elevada temperatura), perde sua forma original. Quando submetido ao processo descontínuo de fritura, comum em lanchonetes e restaurantes, são frequentes as reações de oxidação, hidrólise e polimerização. Dessa forma, o óleo fica inviável para a reutilização no preparo de alimentos e deve ser descartado para a reciclagem. $O$ procedimento de refritura ainda é realizado pela maioria dos proprietários dos estabelecimentos da feira, pois desconhecem o perigo que essa reutilização pode causar à saúde humana.

De acordo com os resultados, podemos observar que $82,3 \%$ das lanchonetes e restaurantes pesquisados não reciclam o óleo usado para fritura e não sabem qual destino é o mais adequado.

Depois do projeto, com a proposta de uma simples mudança de hábito dos comerciantes da praça de alimentação (passar a separar e doar o óleo residual de fritura para o projeto Recicla-Óleo), a proposta de fabricar sabão foi viabilizada. e nos foi disponibilizado o seguinte material: recipientes de 50 litros para a coleta do óleo, cotas de impressão de fôlderes, cartazes para divulgação na comunidade e liberação de pontos de coleta.

Nas oficinas com o grupo de mulheres e com os alunos foram produzidos, por semana, aproximadamente 70 barras de sabão de 200 gramas, durante 07 meses. $O$ sabão, produto gerado dessa atividade, foi comercializado na comunidade por $\mathrm{R} \$ 1,50$ (um real e cinquenta centavos) a unidade. Para confeccionar 24 barras de sabão manufaturado, foram gastos $R \$$ 9,35 (nove reais e trinta e cinco centavos).

De abril de 2014 a abril de 2015, foram coletados, aproximadamente, 500 litros de óleo de cozinha dos estabelecimentos comerciais. Com esse montante de óleo foi possível produzir em torno de 2000 (duas mil) barras de sabão artesanal. 
A coleta de óleo residual de fritura de alimentos (50 litros/mês) viabiliza o potencial da produção de sabão artesanal (280 barras/mês) que está intimamente ligada à geração de renda e à preservação ambiental. Desse modo, o maior ganho é da natureza, pois se reduz a quantidade de poluentes lançados diretamente no ecossistema aquático.

No viés da sustentabilidade pela dimensão econômica, houve uma redução de gastos da prefeitura municipal de Jaguarari (BA) na manutenção da rede coletora de esgoto.

O diretor de Atendimento ao Cidadão, responsável pela administração do espaço, afirmou que, antes da aplicação do projeto, a solicitação ao órgão responsável à Empresa Baiana de Águas e Saneamento S.A-EMBASA, para a limpeza dos canais era feita a cada três meses e, com atuação do projeto Recicla-Óleo, o prazo de solicitação da prefeitura para a desobstrução da rede coletora de esgoto da praça de alimentação da feira livre passou para dez meses.

A partir da reflexão e da convivência com os envolvidos no projeto Recicla-Óleo, vislumbrou-se a possibilidade de se criar uma cooperativa para a produção do sabão manufaturado. Para tanto, fez-se necessário estabelecer novas parcerias com a gerência da EMBASA (empresa responsável pela distribuição de água e saneamento da Bahia), com o Serviço de Atendimento ao Cidadão (SAC) e com a Secretaria de Meio Ambiente do Município.

\section{Conclusões}

Podemos dizer que esse trabalho de reciclagem de óleo residual de frituras dependeu da participação da comunidade. Todas as coletas realizadas, as informações e reflexões foram muito importantes para que as pessoas adquirissem uma maior consciência sobre os problemas advindos da disposição dos resíduos sólidos no meio ambiente, bem como aprendessem sobre processos simples para a reutilização desses resíduos.

A reciclagem de óleo de fritura, trabalhada com os alunos da Escola João Ferreira Matos, proporcionou uma maior interação com a realidade vivida e uma aprendizagem significativa, na medida em que os alunos puderam minimizar os problemas ambientais pela atuação e motivação na comunidade em prol do meio ambiente.

A ação com os proprietários dos estabelecimentos comerciais revelou que eles têm um papel fundamental na transformação dessa realidade, desenvolvendo uma gestão ambiental necessária para a preservação do meio ambiente.

As oficinas de reciclagem de óleo com o grupo de oração de mulheres revelaram uma possibilidade de organização do trabalho, mediante a criação de uma cooperativa capaz de gerar renda com o aprimoramento das técnicas. 
A estratégia utilizada para a proteção do meio ambiente e melhoria da qualidade de vida da comunidade envolveu conhecimento, saberes tradicionais, atitudes, habilidades, participação individual e coletiva. É possível afirmar que a sensibilização inicial foi representativa, pois as ações implementadas, durante o projeto, instigaram a participação de outros setores que não estavam envolvidos diretamente, como o poder público.

Acreditamos que a Educação Ambiental é uma atividade intencional da prática social, que agrega ao desenvolvimento dos indivíduos um caráter social em sua relação com o meio ambiente. É nesse contexto que a Educação Ambiental assume um caráter de grande valia, uma vez que se coloca à disposição da valorização do patrimônio socioambiental, por meio do incentivo de ações que visam o despertar da comunidade para a importância do meio ambiente em que vivem.

\section{Agradecimentos}

Ao rupo de proprietários de restaurantes e lanchonetes do mercado de Jaguarari-Ba, às mulheres do grupo de oração, à Secretaria do Meio Ambiente, à EMBASA e SAC.

\section{Referências}

BRASIL. Secretaria de Educação Fundamental. Parâmetros curriculares nacionais: meio ambiente e saúde. Brasília, 1998.

COELHO, A.S. Coleta de óleo residual de frituras no condomínio residencial metrópoles em Goiânia para aproveitamento industrial. 2010. 22f. Trabalho de Conclusão de Curso (Graduação) - Curso Superior Tecnológico em Gestão Ambiental, Pontifícia Universidade Católica de Goiás, Goiás, 2010.

FILHO, C.G.C.; PAGOTTO, L.D.; BARBOSA, R.M.; FILETTI, R.A.P. Acompanhamento e análise de projeto social de coleta de óleo. 2010 . Disponível em: http://www.ib.unicamp.br/dep biologia animal/BE310. Acesso em: 10 mar. 2015.

LOPES. S.; ROSSO, S. Biologia. volume único. São Paulo: Saraiva, 2005.

LOUREIRO, C.F.B. Sustentabilidade e educação: um olhar da ecologia política. São Paulo: Cortez. 2012. p.75-80.

MANO, E.B.; PACHECO, E.B.A.V.; BONELLI, C.M.C. Meio ambiente, poluição e reciclagem. 1. ed. São Paulo: Edgard Blucher, 2005.

MEDINA, N.M.; SANTOS, E.C. Educação Ambiental: uma metodologia participativa de formação. 2. Ed. Petrópolis: Vozes, 2001.

NEZI, S.M.; UHDRE, D.F.; ROMERO, A.L. Implementação do projeto "reciclagem de óleo e gorduras usadas em frituras através da fabricação de sabão" NA UTFPR. In: Encontro de Produção Cientifica e Tecnologia, 4., 2011, Paraná. Anais... Paraná: [s.n], 2011, p.1-13.

Revbea, São Paulo, V. 12, № 2: 102-113, 2017. 
OIL WORLD. O. Serviço de previsão independente para oleaginosas, óleos e refeições. Disponível em:<http://www.oilworld.biz/app.php>. Acesso em: 14 set. 2014.

RABELO, R.A.; FERREIRA, O.M. Coleta seletiva de óleo residual de fritura para aproveitamento industrial. Goiânia. 2008

REIS, M.F.; FLECK, E. Projeto de entrega voluntária de óleos de fritura exauridos do DMLU - Prefeitura de Porto Alegre. In: Anais do Seminário Regional Sul de Resíduos Sólidos, 3, 2009, Caxias do Sul.

SABESP. Programa de Reciclagem de Óleo de Fritura da Sabesp. Disponívelem:<http://site.sabesp.com.br/uploads/file/asabesp doctos/programa reciclagem oleo completo.pdf> Acesso em: 05 jan. 2015.

SACHS, I. A terceira margem: em busca do desenvolvimento. São Paulo: Companhia das Letras, 2009.

SALLES, F. S. F. Impacto ambiental causado por óleo vegetal. 2010. 31f. Trabalho de Conclusão de Curso (Graduação) - Curso de Gestão Ambiental, Instituto A Vez do Mestre, Rio de Janeiro, 2010. Disponível em: $<$ http://www.avm.edu.br/docpdf/monografias publicadas/k214339.pdf $>$. Acesso em: 25 jan. 2015. 